\title{
Pyrogenic Reaction
}

National Cancer Institute

\section{Source}

National Cancer Institute. Pyrogenic Reaction. NCI Thesaurus. Code C50720.

Fever reaction due to the presence of bacterial endotoxins. 